\title{
Clinical and Laboratory Markers in Determination of Treatment Modalities and Short-Term Prognosis in Patients with Traumatic Acute Subdural Hematoma: Original Study
}

\author{
Bulent Bakar ${ }^{1}$ Ulas Yuksel ${ }^{1} \quad$ Alemiddin Ozdemir ${ }^{1}$ Ibrahim Umud Bulut ${ }^{1}$ Mustafa Ogden ${ }^{1}$ \\ ${ }^{1}$ Department of Neurosurgery, Kirikkale University, Faculty of \\ Medicine, Kirikkale, Turkey \\ Address for correspondence Bulent Bakar, MD, Department of \\ Neurosurgery, Kirikkale University Faculty of Medicine, Yahsihan, \\ 71450-Kirikkale, Turkey (e-mail: bulentbanrs@yahoo.com).
}

Indian J Neurotrauma

\begin{abstract}
Keywords

- acute subdural hematoma

- biochemistry

- biomarker

- prognosis.

Objective In patients with traumatic acute subdural hematoma (ASH), it has not been yet fully elucidated which patients can benefit from surgery or from clinical follow-up. This study was constructed to predict treatment modality and short-term prognosis in patients with ASH using their clinical, radiological, and biochemical laboratory findings during admission to hospital.

Methods Findings of patients with ASH determined on their CT scan between 2015 and 2018 were evaluated. Patients were grouped in terms of ASH-FOL (patients followed-up without surgery, $n=13$ ), ASH-OP (patients treated surgically, $n=10$ ), and ASH-INOP (patients considered as inoperable, $n=5$ ) groups. They also were divided into "survived $(n=14)$ " and "nonsurvived $(n=14)$ " groups.

Results ASH developed as a result of fall from a height in 15 patients and traffic accidents in 13 patients. In deciding for surgery, it was determined that Glasgow coma scale (GCS) scores $<8$, midline shift (MLS) level $>5 \mathrm{~mm}$, MLS-hematoma thickness ratio $>0.22$, leukocyte count $>12730 \mathrm{uL}$, and presence of anisocoria could be used as predictive markers. It was determined that GCS scores $<8$, hematoma thickness value $>8 \mathrm{~mm}$, and the presence of anisocoria could be considered as biomarkers in prediction of mortality likelihood.

Conclusion It could be suggested that GCS scores, MLS level, MLS-hematoma thickness ratio, presence of anisocoria, and leukocyte count value could help in determination of the treatment modality in patients with ASH. Additionally, GCS scores, hematoma thickness value, and presence of anisocoria could each be used as a marker in the prediction of early-stage prognosis and mortality likelihood of these patients.
\end{abstract}

received

June 8,2021

accepted

July 22, 2021
DOI https://doi.org/ 10.1055/s-0041-1739475. ISSN 0973-0508. (c) 2021. Neurotrauma Society of India. All rights reserved.

This is an open access article published by Thieme under the terms of the Creative Commons Attribution-NonDerivative-NonCommercial-License, permitting copying and reproduction so long as the original work is given appropriate credit. Contents may not be used for commercial purposes, or adapted, remixed, transformed or built upon. (https://creativecommons.org/ licenses/by-nc-nd/4.0/)

Thieme Medical and Scientific Publishers Pvt. Ltd., A-12, 2nd Floor, Sector 2, Noida-201301 UP, India 


\section{Introduction}

Despite modern diagnostic and treatment methods, traumatic acute subdural hematoma (ASH) is a clinical entity which can still be seen with high mortality rates (36-79\%). ${ }^{1-4}$ Previous studies have shown that mortality was related to age, type and severity of the injury, time from injury to surgery, the planned surgical intervention, and postoperative duration of stay in the intensive care unit (ICU) in these patients. ${ }^{2}$ However, in literature, it is still debated which treatment option will be applied to which patient and, therefore, which patients can benefit from surgery or which patients can benefit from clinical follow-up, and this has not been fully elucidated. Therefore, the need to determine predictive factors of prognosis to be able to correct the neurological situation and reduce the mortality rates have started to be discussed in the literature. Many studies addressing this discussion have examined several factors that could be markers of prognosis but conflicting results have been reported. ${ }^{5}$

This study was constructed in order to predict the shortterm prognosis and decide the management regimen to be applied (i.e., surgery or follow-up conservatively) to the patients with traumatic ASH, using their clinical, radiologic, and biochemical laboratory findings which were obtained at first admission to hospital.

\section{Material and Method}

\section{Patient Groups}

Approval for this single-center, retrospective study was granted by the Clinical Research Local Ethics Committee (Date: 24/07/2019, decision no: 2019.07.01).

"The International Statistical Classification of Diseases and Related Health Problems (ICD-10)" coding was used to scan the hospital records (I62.0: subdural hemorrhage (acute) (nontraumatic); S06.5: traumatic subdural bleeding). The data was examined of patients who were brought to the emergency department (ED) for reasons of a "fall from a height" or "traffic accident" between January 2015 and June 2018. Then, patients who were determined with ASH on brain computed tomography (CT) and were then admitted to the surgical clinic or the ICU and treated medically and/or surgically were included in this study. The patients were excluded from this study if data was incomplete, if they were dead in ED after a diagnosis of ASH, if they had head and general body trauma together or life-threatening major organ injuries, if they had another type intracranial hemorrhage secondary to the trauma, if they had subdural hematoma not secondary to the trauma, trauma not related to falling from a height or traffic accident, if they had nonacute subdural bleeding, if they had been incorrectly coded with ICD-10, or if they were in the pediatric age group ( $<16$ years).

The patients included in this study were grouped, according to the treatment method as follows:

- ASH-INOP group (patients with ASH but for whom it was considered that they would not benefit from surgical treatment due to their poor condition, $n=5$ )
- ASH-FOL group (patients with ASH for whom the decision of clinical follow-up and medical supportive treatment was taken, $n=13$ )

- ASH-OP group (patients with ASH for whom the decision of the surgical treatment was taken, $n=10$ ).

Patients were also separated into two groups, according to the short-term outcome:

- Nonsurvived group (patients who died in hospital following treatment, $n=14$ )

- Survived group (after the treatment, the patients who survived and were discharged from the hospital, $n=14$ )

\section{Materials}

Age, gender, GCS scores on admission to hospital, pupillary dilation/reactivity findings (i.e., anisocoria), duration of stay in ICU, duration of stay in the hospital, and Glasgow outcome scale (GOS) scores on discharge from the hospital were recorded for all patients. ${ }^{6,7}$ The brain $\mathrm{CT}$ images obtained on admission to hospital were examined and the hematoma thickness, midline shift (MLS) level, and MLS-hematoma thickness ratio were recorded. Blood biochemistry results obtained on admission to hospital and neutrophillymphocyte ratio and platelet-lymphocyte ratio results were examined.

\section{Biochemical Analysis}

The venous blood samples taken from the patients on first admission to hospital were examined, and the study results were obtained from these samples analyses. The blood hemoglobin level (reference range: $10-18 \mathrm{~g} / \mathrm{dL}$ ), leukocyte (reference range: 4400-11300 uL), neutrophil (reference range: 110-9600 uL), lymphocyte (reference range: 500$6000 \mathrm{uL}$ ), monocyte (reference range: 100-1400 uL), eosinophil (reference range: $0-1000 \mathrm{uL}$ ), basophil (reference range: 0-300 uL), and thrombocyte (reference range: $150,000-500,000 \mathrm{uL}$ ) count values were determined with an analysis device (Mindray BC-6800, Shenzen, China).

Serum glucose (reference range: $74-109 \mathrm{mg} / \mathrm{dL}$ ), blood urea nitrogen (BUN) (reference range: $17-43 \mathrm{mg} / \mathrm{dL}$ ), creatinine (reference range: $0.84-1.24 \mathrm{mg} / \mathrm{dL}$ ), alanine aminotransferase (ALT) (reference range: 5-41 U/L), aspartate aminotransferase (AST) (reference range: 5-40 $\mathrm{U} / \mathrm{L}$ ), C-reactive protein (CRP) (reference range: 0.15$5 \mathrm{mg} / \mathrm{dL}$ ), sodium (reference range: $136-146 \mathrm{mmol} / \mathrm{L}$ ), and potassium (reference range: $3.5-5.1 \mathrm{mmol} / \mathrm{L}$ ) levels were obtained using original kits (Roche) on an automatic device (Roche Diagnostic COBAS c501).

\section{Treatment Modalities}

The patients with very small diameter ASH and/or no clinical signs were followed-up conservatively. Furthermore, surgical treatment was not performed on the patients with ASH but on those who would not possibly benefit from surgical treatment (inoperable), and very elderly patients (> 90 years), and these patients were followed-up conservatively (-Fig. $\mathbf{1}$ ). 

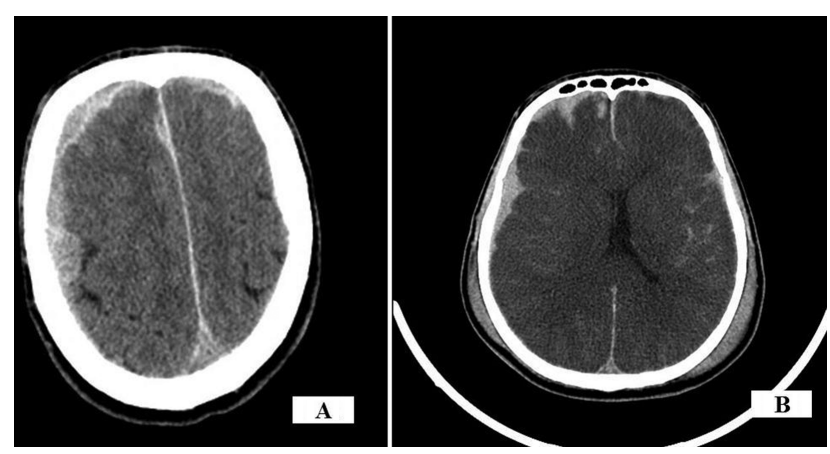

Fig. 1 CT images of a patient with acute subdural hematoma who could not be operated on; (A) on admission to hospital, and (B) 2 days after admission.

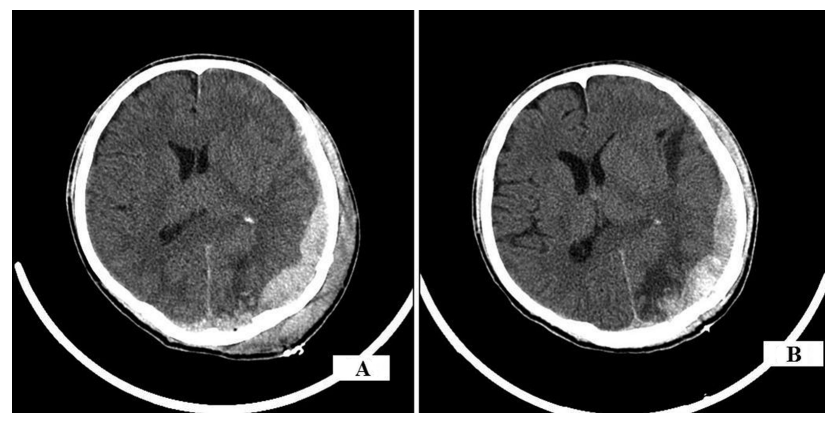

Fig. 2 CT images of a patient with acute subdural hematoma for whom follow-up was decided without operation; (A) on admission to hospital, and (B) during follow-up.

The patients in the ASH-FOL and ASH-INOP groups underwent control brain CT twice at 3-hour intervals and at the end of 24 hours following the first CT scan. The conservative treatment consisted of hyperosmolar diuretic treatment, sedation and analgesia or barbiturate coma, bed height, and cerebrospinal fluid (CSF) drainage through the external ventricular drainage catheter. Prophylactic anticoagulation started 48 to 72 hours after the treatment, provided that the intracranial hemorrhagic lesions had stability (-Fig. 2).

Surgical treatment was performed on the patients with hematoma $>10 \mathrm{~mm}$ in thickness on brain CT imaging, those with $>5 \mathrm{~mm}$ MLS on CT, a decrease of $>2$ units in GCS scores, and /or determined pupillary dilatation (anisocoria) (-Fig. 3). ${ }^{8,9}$ All patients who were considered for surgical treatment were administered general anesthesia, and then a wide frontotemporoparietal craniectomy was performed on the side of the ASH. After the appropriate opening of the dura, the hematoma was drained, and hemostasis was obtained (-Fig. 3). Lobectomy was not performed for any patient. Following hemostasis, duraplasty was applied with a graft taken from the galea or tensor fascia lata muscle. Because the brain was swollen in all operated patients, the bone flap was left over the abdominal fascia or over the tensor fascia lata, the surgical areas were closed anatomically, and the operation was terminated. Thereafter, the intubated patients were observed for at least 48 hours in ICU under sedation anesthesia provided by 0.03 to $0.05 \mathrm{mg} / \mathrm{kg}$ midazolam (Dormicum, Roche).

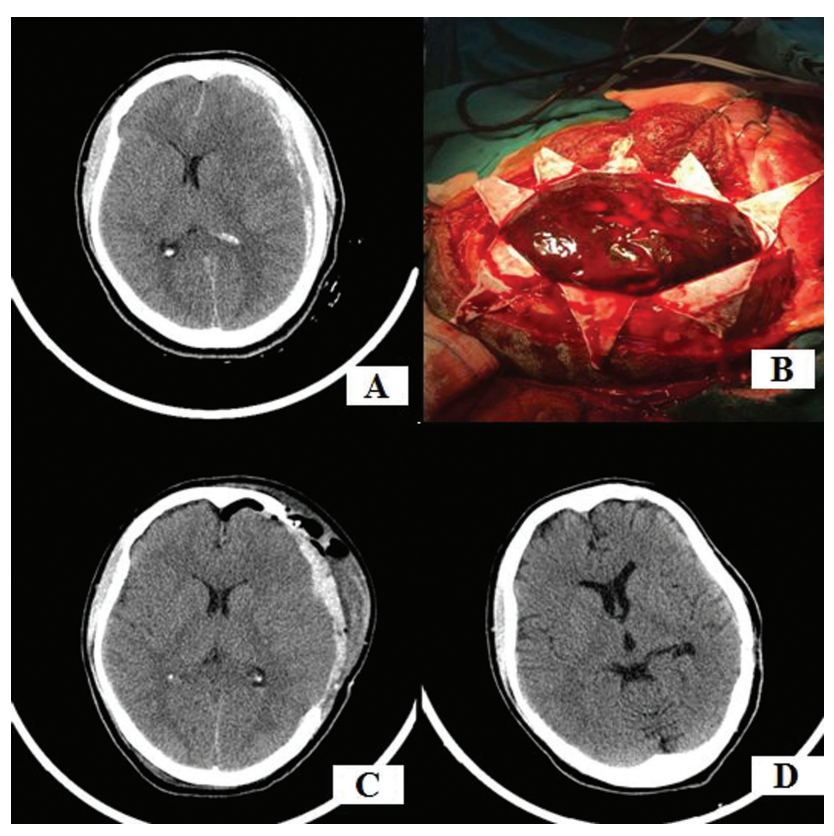

Fig. 3 CT images of a patient with acute subdural hematoma who was operated on; (A) on admission to hospital, (B) intraoperative image of decompressive craniectomy, (C) early postoperative image, and (D) follow-up image immediately before discharge.

\section{Statistical Analysis}

The parametric data was analyzed using the independent samples $t$-test or one-way analysis of variance (ANOVA) test. For posthoc comparisons, the Tukey multiple comparisons test was used $(p<0.05)$. The Mann-Whitney U test or KruskalWallis test was applied to the comparisons of nonparametric data among groups $(p<0.05)$. For posthoc comparisons, the Mann-Whitney U test and Bonferroni correction test were used $(p<0.016)$. Pearson's Chi-square test was used to evaluate differences between groups in terms of the categorical data $(p<0.05)$.

The Wilcoxon signed rank test was performed to determine the significant difference between the repeated measures for each group $(p<0.05)$.

Spearman's rho correlation test was used to determine correlations between parameters $(p<0.05)$, and to determine the independent variables, which could help to determine the treatment method (surgical/conservative treatment) to be applied to the patient. The ROC curve test was applied $(p<0.05)$ to predict the mortality likelihood. Furthermore, the logistic regression test was applied to determine which were the best parameters to be able to make these decisions $(p<0.05)$. Finally, the direction and strength of the association between ASH and complication risk, surgical intervention risk and mortality risk were quantified using odds ratio (OR) test.

\section{Results}

A total of 28 patients (ASH developed as a result of a fall from height in 15 patients and traffic accidents in 13 patients), comprising 23 males and 5 females, were included in this study (-Table $\mathbf{1}$ ). The mean age of the patients was 


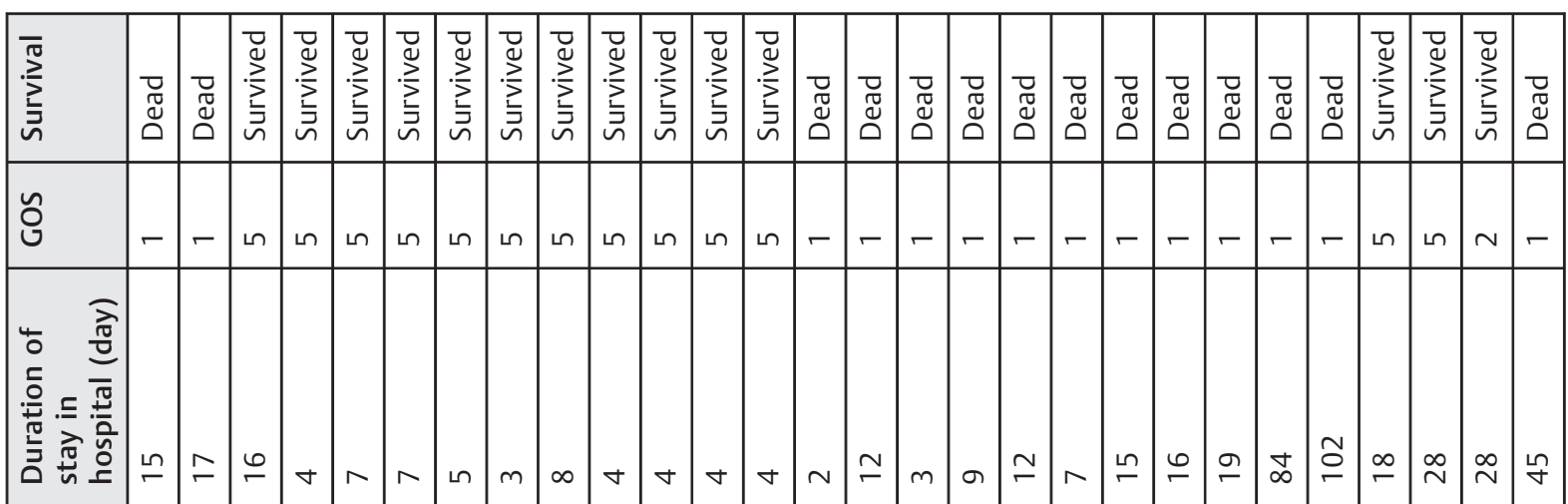

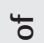

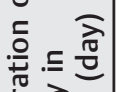

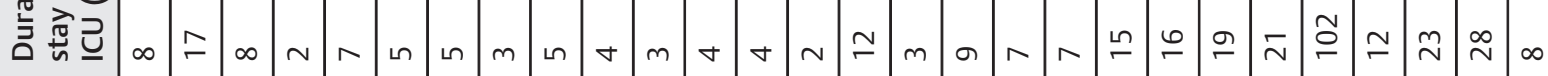
는

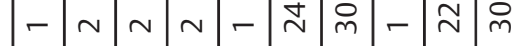

离

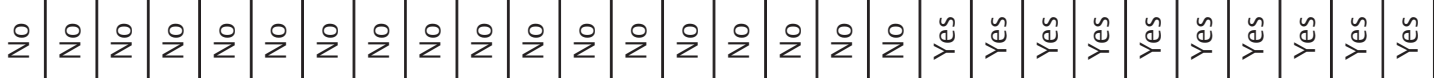

$\frac{\pi}{\grave{0}}$

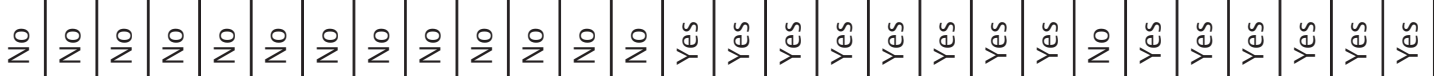

$\frac{\widehat{\underline{E}}}{\underline{\underline{E}}}$

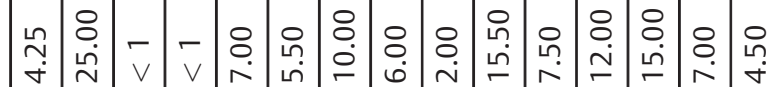


$52.61 \pm 22.60$ years, the majority of the patients were male $(n=23)$, and the common mechanism of injury was a fall from height $(n=15)$. The mean GCS score was 12 (range, 315), hematoma thickness was $10.22 \pm 5.32 \mathrm{~mm}$, MLS was $4.33 \pm 6.30 \mathrm{~mm}$, MLS-hematoma thickness ratio was 0.20 (0.04-2.00), and the majority of patients had anisocoria. The median duration of stay in hospital was 10.50 days (range 2102), and mortality in the hospital was determined in 7 of the operated patients, in 2 of the patients followed-up without surgery, and in all 5 of the patients classified as inoperable. As shown in - Figs. 1, 2, and 3, all of the subdural hematomas in the radiological examinations were located in the hemispheric and supratentorial locations (i.e., 18 patients had frontotemporoparietal, 4 patients had frontoparietal, 3 patients had temporoparietal, 1 patient had frontotemporal, 1 patient had occipitotemporal, and 1 patient had occipitoparietal). It was learned from the patients' past history that two patients had coronary artery disease, two had essential hypertension, two had diabetes mellitus, and one had chronic renal failure. It also was learned that one of the patients in the ASH-INOP group received ticagrelor and one of the patients in the ASH-FOL group used acetylsalicylic acid for coronary artery disease. In order to stop the increase of the hematoma volume of these two patients, the effects of drugs were tried to be reversed by fresh platelet apheresis infusion. When the patients were evaluated according to age group (1864 years versus $>64$ years), gender, or etiological cause (traffic accident versus fall from height), no statistically significant difference was determined in any parameter.

Correlation test results applied to all the parameters of all the patients revealed a positive correlation between GCS and GOS scores $(r=0.790, p<0.001)$, between GCS scores and survival $(r=0.747, p<0.001)$, between hematoma thickness and MLS ( $r=0.444, p=0.018)$, between hematoma thickness and anisocoria $(r=0.438, p=0.020)$, and between the decision-making for surgical treatment and MLS-hematoma thickness ratio $(r=0.579, p=0.001)$. MLS was positively correlated with decision-making for surgical treatment $(r=0.747, p<0.001)$, anisocoria $(r=0.798, p<0.001)$, and MLS-hematoma thickness ratio $(r=0.701, \quad p<0.001)$. Anisocoria was positively correlated with leukocyte count $(r=0.442, \quad p=0.018), \quad$ MLS-hematoma thickness ratio $(r=0.426, \quad p=0.024)$, and decision-making for surgical treatment $(r=0.596, p=0.001)$. Duration of stay in ICU was positively correlated with MLS $(r=0.653, p<0.001)$, pupillary dilatation $(r=0.424, p=0.024)$, MLS-hematoma thickness ratio $(r=0.448, p=0.017)$, and decision-making for surgical treatment $(r=0.708, p<0.001)$. Duration of stay in hospital was positively correlated with hematoma thickness $(r=0.417$, $p=0.027)$, MLS $(r=0.620, p<0.001)$, anisocoria $(r=0.417$, $p=0.027)$, MLS-hematoma thickness ratio $(r=0.406$, $p=0.032$ ), and decision-making for surgical treatment $(r=0.718, p<0.001)$.

A negative correlation was determined between GCS scores and hematoma thickness $(r=-0.453, p=0.016)$, MLS $(r=-0.686, \quad p<0.001)$, anisocoria $(r=-0.874$, $p<0.001)$, surgical treatment $(r=-0.466, p=0.013)$, leukocyte count $(r=-0.454, p=0.015)$, glucose $(r=-$
0.653, $p=0.001)$, alanine aminotransferase (ALT) $(r=-$ $0.568, p=0.007)$, aspartate transaminase (AST) $(r=-0.525$, $p=0.014)$, and duration of stay in ICU $(r=-0.448, p=0.017)$. Hematoma thickness was negatively correlated with anisocoria $(r=-0.438, p=0.020)$ and survival $(r=-0.399$, $p=0.036)$. A negative correlation was determined between anisocoria and survival ( $r=-0.571, p=0.001)$, between MLS and survival $(r=-0.408, p=0.031)$, between Glasgow outcome scale (GOS) scores and hematoma thickness $(r=-0.432, p=0.022)$, between GOS scores and MLS $(r=-$ $0.449, p=0.016)$, between GOS scores and anisocoria $(r=-$ $0.617, p<0.001$ ), and between GOS scores and duration of stay in ICU $(r=-0.425, p=0.024)$.

The ROC Curve test results showed that if GCS score was found $<8 \quad$ (area $=0.772, \quad p=0.019, \quad 70 \%$ specificity, 70\% sensitivity), if MLS level was measured $>5 \mathrm{~mm}$ (area $=0.914$, $p<0.001,80 \%$ sensitivity, $90 \%$ specificity), if MLS-hematoma thickness ratio was $>0.22$ (area $=0.853, p=0.002,80 \%$ sensitivity, $83 \%$ specificity), if anisocoria was detected (area $=0.811, p=0.007,100 \%$ sensitivity, $100 \%$ specificity), and if leukocyte count was $>12730 \mathrm{uL}$ (area $=0.767$, $p<0.021,80 \%$ sensitivity, $67 \%$ specificity), they could be considered biomarkers in predicting the decision-making for surgical treatment. The logistic regression test revealed that anisocoria $(B=3.153$, Wald $=7.161, p=0.007)$ and leukocyte count $(B=0.000$, Wald $=4.401, p=0.036)$ were determined to be the best parameters in decision-making for surgical treatment (-Table 2, - Fig. 4). OR test results revealed that if MLS was measured $>5 \mathrm{~mm}$, it was associated with more than 32-fold risk of surgical intervention $(\mathrm{OR}=32.00 ; 95 \%$ $\mathrm{CI}=3.78-270.85$ ). If MLS-hematoma thickness ratio was $\geq$ 0.21 , it was associated with more than 14 -fold risk of surgical intervention ( $\mathrm{OR}=14.00 ; 95 \% \mathrm{CI}=2.08-94.24)$. If anisocoria was detected, it was associated with more than 23-fold risk of surgical intervention $(\mathrm{OR}=23.40 ; 95 \% \mathrm{CI}=2.33-235.54)$. If leukocyte count value was $\geq 12730 \mathrm{uL}$, it was associated with more than 16-fold risk of surgical intervention $(\mathrm{OR}=16.00$; 95\% CI = 1.61-159.31) (-Table 3).

When the patients were evaluated in the three groups, according to the treatment modalities, GCS scores $(F=62.304$, $p<0.001)$, MLS level $(\mathrm{F}=9.405, p=0.001)$, anisocoria $\left(\mathrm{X}^{2}=-\right.$ 24.400, $\quad p<0.001), \quad$ MLS-hematoma thickness ratio $\left(X^{2}=11.630, p=0.003\right)$, ALT level $\left(X^{2}=6.236, p=0.044\right)$, duration of stay in ICU $\left(\mathrm{X}^{2}=13.628, p=0.001\right)$, duration of stay in hospital $\left(X^{2}=15.900, p<0.001\right)$, GOS scores $\left(X^{2}=13.679, p=0.001\right)$, and survival values $\left(X^{2}=12.831\right.$, $p=0.002$ ) were different among the groups (-Table 4). In the paired group comparisons, GCS scores, MLS level, MLShematoma thickness ratio, duration of stay in ICU, duration of stay in hospital, and GOS score values were different between the ASH-OP and ASH-FOL groups. The duration of stay in ICU and duration of stay in hospital were different between the ASH-OP and ASH-INOP groups. GCS scores, MLS values, and GOS score values were different between the ASH-FOL and ASH-INOP groups (- Table 5). Furthermore, the median value of the first measured hematoma thickness was $5.50 \mathrm{~mm}(2.50-$ 19.00 ) and the median value of the last measured hematoma was $4.00 \mathrm{~mm}(0-14)$ in the ASH-FOL group. A statistically 
Predictive Markers in Acute Subdural Hematoma Bakar et al.

Table 2 The table demonstrates the ROC curve test results in predicting the short-term prognosis of the patients and the decisionmaking for surgical treatment

\begin{tabular}{|l|l|l|l|l|l|}
\hline Decision & Variable & Area & $p$ & Cutoff value & \\
\hline Follow-up & GCS score & 0.772 & $<0.019$ & $>8$ & $\begin{array}{l}\text { Sensitivity }=70 \% \\
\text { Specificity }=70 \%\end{array}$ \\
\hline Surgery & MLS (mm) & 0.914 & $<0.001$ & $>5$ & $\begin{array}{l}\text { Sensitivity }=80 \% \\
\text { Specificity }=90 \%\end{array}$ \\
\hline & MLS-hematoma thickness ratio & 0.853 & 0.002 & $>0.21$ & $\begin{array}{l}\text { Sensitivity }=80 \% \\
\text { Specificity }=78 \%\end{array}$ \\
\hline & Presence of anisocoria $(0=$ no, $1=$ yes) & 0.811 & $<0.007$ & Yes & $\begin{array}{l}\text { Sensitivity }=100 \% \\
\text { Specificity }=100 \%\end{array}$ \\
\hline & Leukocyte count (uL) & 0.767 & 0.021 & $>12730$ & $\begin{array}{l}\text { Sensitivity }=80 \% \\
\text { Specificity }=67 \%\end{array}$ \\
\hline Survived & GCS score & 0.918 & $<0.001$ & $>8$ & $\begin{array}{l}\text { Sensitivity }=85 \% \\
\text { Specificity }=72 \%\end{array}$ \\
\hline Nonsurvived & Hematoma thickness $(\mathrm{mm})$ & 0.730 & 0.039 & $>8$ & $\begin{array}{l}\text { Sensitivity }=65 \% \\
\text { Specificity }=79 \%\end{array}$ \\
\hline & & & & & Sensitivity $=100 \%$ \\
& & & & & Specificity $=100 \%$ \\
\hline
\end{tabular}

Abbreviations: GCS, Glasgow coma scale score; MLS, midline shift.

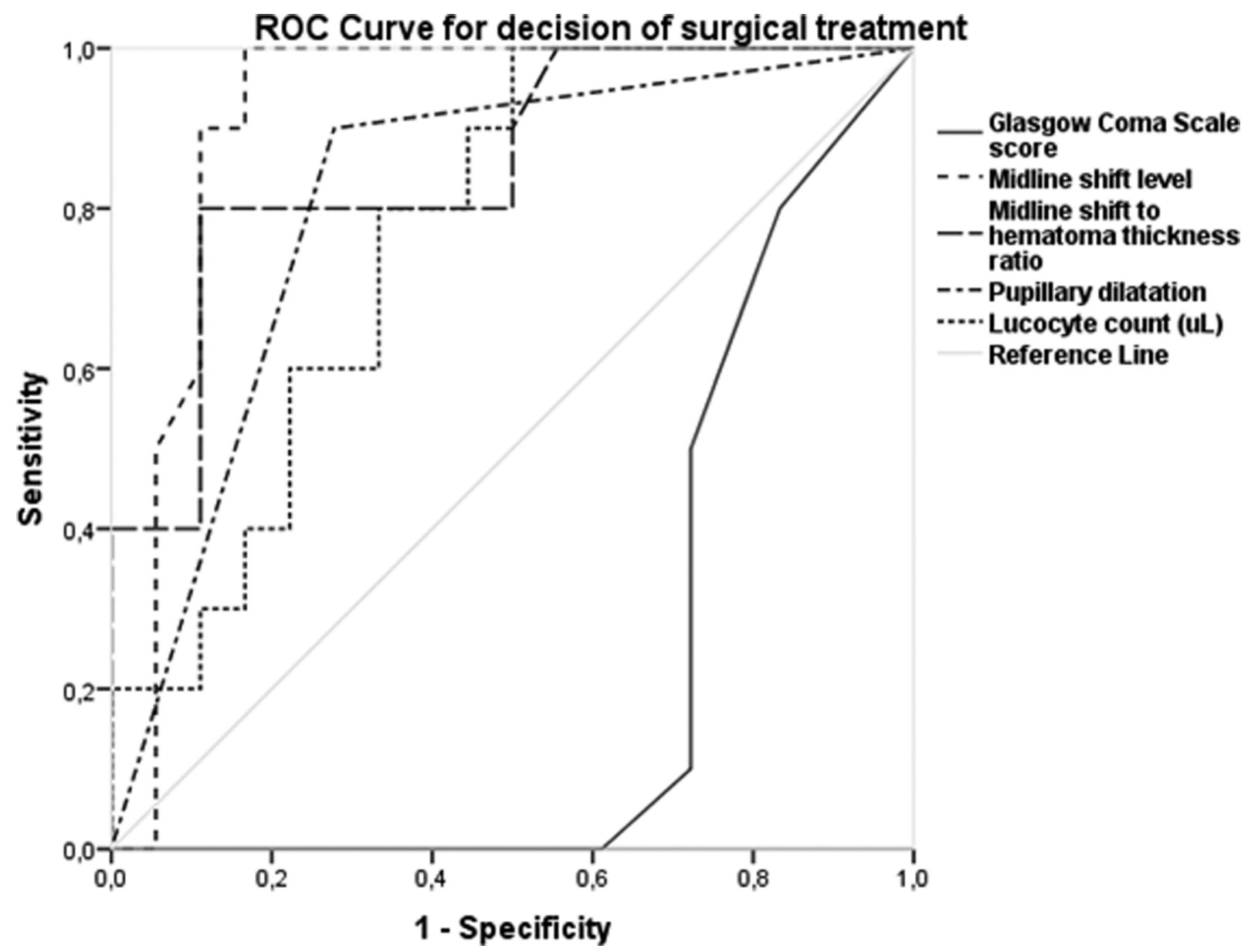

Fig. 4 The receiver operating characteristic (ROC) curve plot shows the parameters that can predict the decision-making for surgical intervention in patients with acute subdural hematoma. 
Table 3 The table shows the OR test results and its corresponding 95\% CI for the direction and strength of the association between the patients' data and decision-making for surgical intervention

\begin{tabular}{|l|l|l|l|}
\hline & Surgical intervention risk & \multicolumn{2}{|c|}{$95 \% \mathrm{Cl}$} \\
\hline Variable & OR value & Lower & Upper \\
\hline MLS value $\geq 5 \mathrm{~mm}$ & 32.00 & 3.78 & 270.85 \\
\hline MLS-hematoma thickness ratio $\geq 0.21$ & 14.00 & 2.08 & 94.24 \\
\hline Presence of anisocoria & 23.40 & 2.33 & 235.54 \\
\hline Leukocyte count value $\geq 12730 \mathrm{uL}$ & 16.00 & 1.61 & 159.31 \\
\hline
\end{tabular}

Abbreviations: $\mathrm{Cl}$, confidence intervals; FFH: fall from a height; GCS, Glasgow coma scale; OR, odds ratio; TA, traffic accident.

significant difference was found between the first measured hematoma thickness and the last measured hematoma thickness $(Z=-2.449, p=0.014)$, and it was thought that hematoma thickness decreased significantly during the follow-up in ASH-FOL group (- Table 5).

The GCS scores $(t=-4.286, p<0.001)$, hematoma thickness values $(t=2.097, \quad p=0.046)$, anisocoria $\left(X^{2}=9.143, \quad p=0.002\right)$, and GOS scores $(Z=-5.112$, $p<0.001$ ) were different between the survived and nonsurvived groups (-Table 6 ).

The results of the ROC curve test determined that if GCS score was $<8$ (area $=0.918, p<0.001,85 \%$ specificity, $72 \%$ sensitivity), if hematoma thickness value was measured $>8 \mathrm{~mm} \quad($ area $=0.270, \quad p=0.039, \quad 65 \%$ sensitivity, 79\% specificity), and if anisocoria was detected (area $=0.214$, $p=0.010,100 \%$ sensitivity, $100 \%$ specificity), they could be considered as markers in predicting the mortality risk. As a result of the logistic regression test, GCS was determined to be the best parameter in the prediction of mortality likelihood $\quad(\mathrm{B}=-\quad 3.095, \quad$ Wald $=8.941, \quad p=0.003)$ (-Table 2, - Table 3, -Fig. 5).

\section{Discussion}

In literature, the decision for surgical treatment of patients with ASH is based on the GCS score, pupil examination, and CT findings. ${ }^{8}$ It has been reported that independently of GCS scores, hematoma thickness $>10 \mathrm{~mm}$ or a MLS value $>5 \mathrm{~mm}$ could be critical parameters in decision-making for surgery. ${ }^{9-11}$ However, because of negative outcomes, it is recommended that young or elderly patients with GCS 3 and bilateral fixed and dilated pupils are treated less aggressively. ${ }^{12-16}$ However, it has been shown that good functional results can be obtained following aggressive surgical treatment in up to $8 \%$ of patients with ASH and GCS $3 .{ }^{17}$

In the present study, the GCS and the GOS scores of the ASH-FOL group were higher, and duration of stay in hospital and mortality rate were lower than those of the other groups. In the ASH-OP group, the GCS scores were approximately 7 , and MLS, hematoma thickness, GOS score and survival values were seen to be similar but relatively higher than those of the nonoperated patient group. In addition, the patients in this group were determined with a longer duration of stay in ICU and hospital and a higher MLS-hematoma thickness ratio value than the other two groups. These findings suggest that at the time of hospital admission, GCS scores, hematoma thickness, MLS level, the MLS-hematoma thickness ratio, and leukocyte count values could make significant contributions to the decision-making about the treatment modality. In contrast, the ASH-INOP group was formed of patients who would have required an operation but for various reasons had to be followed-up conservatively. The GCS scores of the ASH-INOP group were significantly lower than those of the other groups, and all of these patients died in hospital. Indeed, although their MLS and hematoma thickness value of patients in ASH-INOP were similar to the patients in the ASH-OP group, surgical treatment was not performed to these patients because of their worse clinical condition. On the other hand, it was seen that because of their good neurological condition, some patients (i.e., ASH-FOL group patients) were followed-up without surgery, even though the hematoma thickness was $>10 \mathrm{~mm}$ and MLS was $>5 \mathrm{~mm}$. Therefore, it was thought that prediction of the early prognosis using the first clinical, radiological, and laboratory findings of the patient could be very important in determining the treatment modality to be applied to these patients.

Correlation analysis applied to all the parameters of all the patients revealed a positive correlation between GCS scores and GOS scores and a negative correlation between GCS scores and hematoma thickness, MLS level, and finding of anisocoria. Therefore, when the GCS scores were high, the short-term prognosis could be better. Conversely, when hematoma thickness and/or the MLS was greater or anisocoria detected, it could be considered that the GCS scores of these patients could be lower, there could be a need for surgical treatment, and the duration of stay in ICU and hospital could be prolonged. These findings suggest that low GCS score, a high MLS value, a high MLS-hematoma thickness ratio value, and development of anisocoria could be suitable biomarkers for decision-making for surgical treatment. The results of the ROC curve analysis confirmed that GCS score, hematoma thickness and MLS values, the finding of anisocoria, the MLS-hematoma thickness ratio value, and leukocyte count value could be helpful in decision-making for surgical treatment in ASH patients. Interestingly, the OR test results also supported this suggestion impressively. Thus, it was concluded that each of these parameters could be used as predictive markers in decision-making for surgical treatment.

Previous studies have reported a significant decrease in morbidity and mortality rates in patients operated on within 
Predictive Markers in Acute Subdural Hematoma Bakar et al.

Table 4 The table shows the demographic, radiological, and biochemical laboratory test findings of the patients according to the ASH-FOL, ASH-OP, and ASH-INOP groups.

\begin{tabular}{|c|c|c|c|c|c|}
\hline & & ASH-FOL & ASH-INOP & ASH-OP & \\
\hline Variable & & $\begin{array}{l}\text { Mean } \pm \text { SD } / \\
\text { Median (min-max) } \\
N(\%)\end{array}$ & $\begin{array}{l}\text { Mean } \pm \text { SD } / \\
\text { Median (min-max)/ } \\
N(\%)\end{array}$ & $\begin{array}{l}\text { Mean } \pm S D / \\
\text { Median } \\
(\min -\max ) / N(\%)\end{array}$ & $p$ \\
\hline Age (year) & & $56.46 \pm 21.17$ & $57.60 \pm 26.49$ & $45.10 \pm 22.91$ & $0.438^{\mathrm{a}}$ \\
\hline \multirow[t]{2}{*}{ Gender } & Male & $11(39.3 \%)$ & $3(10.7 \%)$ & $9(32.1 \%)$ & $0.342^{c}$ \\
\hline & Female & $2(7.1 \%)$ & $2(7.1 \%)$ & $1(10.0 \%)$ & \\
\hline \multirow[t]{2}{*}{ Etiology } & $\mathrm{FFH}$ & $8(28.6 \%)$ & $3(10.7 \%)$ & $4(14.3 \%)$ & $0.561^{c}$ \\
\hline & TA & $5(17.9 \%)$ & $2(7.1 \%)$ & $6(21.4 \%)$ & \\
\hline GCS score & & $14.62 \pm 0.77$ & $3.40 \pm 0.55$ & $6.40 \pm 3.60$ & $<0.001^{a}$ \\
\hline $\begin{array}{l}\text { Hematoma thickness } \\
\text { value }(\mathrm{mm})\end{array}$ & & $7.68 \pm 4.75$ & $12.90 \pm 5.20$ & $12.20 \pm 5.03$ & $0.054^{\mathrm{a}}$ \\
\hline MLS level (mm) & & $0.00 \pm 0.00$ & $7.65 \pm 10.02$ & $8.50 \pm 4.50$ & $0.001^{a}$ \\
\hline $\begin{array}{l}\text { MLS-hematoma } \\
\text { thickness ratio }\end{array}$ & & $0.16(0.04-0.22)$ & $0.23(0.11-1.38)$ & $0.56(0.16-2.00)$ & $0.003^{b}$ \\
\hline \multirow[t]{2}{*}{ Anisocoria } & No & $13(46.4 \%)$ & $0(0 \%)$ & $1(3.6 \%)$ & $<0.001^{c}$ \\
\hline & Yes & $0(0 \%)$ & $5(17.9 \%)$ & $9(32.1 \%)$ & \\
\hline Hemoglobin level (g/dL) & & $14.52 \pm 1.96$ & $12.90 \pm 1.92$ & $14.01 \pm 1.96$ & $0.305^{a}$ \\
\hline Leukocyte count (uL) & & $12079 \pm 4761.64$ & $13450 \pm 6076.06$ & $17525 \pm 5244.03$ & $0.057^{\mathrm{a}}$ \\
\hline Neutrophil count (uL) & & $9280 \pm 5107.58$ & $8466 \pm 5644.80$ & $12005 \pm 7388.55$ & $0.468^{a}$ \\
\hline Lymphocyte count (uL) & & $1948 \pm 1406.64$ & $4193 \pm 3269.81$ & $3386 \pm 3461.77$ & $0.220^{\mathrm{a}}$ \\
\hline Monocyte count (uL) & & $625 \pm 231.75$ & $570 \pm 228.58$ & $715 \pm 406.17$ & $0.649^{a}$ \\
\hline Eosinophil count (uL) & & $197 \pm 181.22$ & $174 \pm 280.14$ & $126 \pm 134.14$ & $0.665^{\mathrm{a}}$ \\
\hline Basophil count (uL) & & $71 \pm 109.73$ & $50 \pm 58.10$ & $65 \pm 57.48517$ & $0.898^{\mathrm{a}}$ \\
\hline Platelet count (uL) & & $218769 \pm 69336.32$ & $219400 \pm 53388.20$ & $242713 \pm 122152.29$ & $0.801^{\mathrm{a}}$ \\
\hline $\begin{array}{l}\text { Neutrophil to } \\
\text { lymphocyte ratio }\end{array}$ & & $3.24(0.91-44.72)$ & $2.16(0.85-11.74)$ & $5.78(0.74-73.74)$ & $0.469^{b}$ \\
\hline $\begin{array}{l}\text { Platelet to } \\
\text { lymphocyte ratio }\end{array}$ & & $116.67(39.85-553.53)$ & $47.58(35.56-299.67)$ & $63.42(2.20-773.97)$ & $0.370^{\mathrm{b}}$ \\
\hline Glucose (mg/dL) & & $123.06 \pm 34.26$ & $220.20 \pm 156.45$ & $167.35 \pm 74.98$ & $0.250^{\mathrm{a}}$ \\
\hline Sodium (mmol/L) & & $141(138-146)$ & $142(138-143)$ & $138(145-154)$ & $0.385^{\mathrm{b}}$ \\
\hline Potassium (mmol/L) & & $4.37(3.68-5.54)$ & $4.26(2.88-5.15)$ & $4.25(3.33-5.90)$ & $0.823^{b}$ \\
\hline $\begin{array}{l}\text { Blood urea } \\
\text { nitrogen }(\mathrm{mg} / \mathrm{dL})\end{array}$ & & $34.73 \pm 15.60$ & $39.19 \pm 18.33$ & $30.88 \pm 11.37$ & $0.576^{\mathrm{a}}$ \\
\hline Creatinine (mg/dL) & & $1(0.72-1.24)$ & $0.81(0.53-1.27)$ & $0.94(0.58-2.62)$ & $0.781^{\mathrm{b}}$ \\
\hline $\begin{array}{l}\text { Aspartate } \\
\text { aminotransferase (u/L) }\end{array}$ & & 19 (14-39) & $34(26-469)$ & $25(19-158)$ & $0.088^{\mathrm{b}}$ \\
\hline $\begin{array}{l}\text { Alanine } \\
\text { aminotransferase (u/L) }\end{array}$ & & $13(9-19)$ & $20(13-339)$ & $23(10-132)$ & $0.044^{b}$ \\
\hline C-reactive protein (mg/dL) & & $11.75 \pm 13.89$ & $12.32 \pm 20.01$ & $50.44 \pm 77.00$ & $0.312^{\mathrm{a}}$ \\
\hline $\begin{array}{l}\text { Duration of } \\
\text { stay in ICU (day) }\end{array}$ & & $5(2-17)$ & $7(2-12)$ & $17.50(7-102)$ & $0.001^{b}$ \\
\hline $\begin{array}{l}\text { Duration of stay } \\
\text { in hospital (day) }\end{array}$ & & $5(3-17)$ & $7(2-12)$ & $23.50(12-102)$ & $<0.001^{\mathrm{b}}$ \\
\hline GOS score & & $5(1-5)$ & $1(1-1)$ & $1(1-5)$ & $0.001^{b}$ \\
\hline \multirow[t]{2}{*}{ Survival } & Dead & $2(7.1 \%)$ & $5(17.9 \%)$ & 7 (25.0\%) & $0.002^{c}$ \\
\hline & Survived & $11(39.3 \%)$ & $0(0.0 \%)$ & $3(10.7 \%)$ & \\
\hline
\end{tabular}

Abbreviations: ICU, intensive care unit; FFH, fall from a height; GCS, Glasgow coma scale; GOS, Glasgow outcome scale; Max, maximum; Min, minimum; MLS, midline shift; N, number of patients; SD, standard deviation; TA, traffic accidents.

${ }^{\mathrm{a}}$ One way analysis of variance (ANOVA) test $(p<0.05)$

${ }^{\text {b} K r u s k a l-W a l l i s ~ t e s t ~}(p<0.05)$

'Pearson's Chi-square test $(p<0.05)$ 
Table 5 The table shows the results of the binary comparison of the ASH-FOL, ASH-OP, and ASH-INOP groups' findings

\begin{tabular}{|l|l|l|l|}
\hline Variable & Groups (I/J) & Mean difference/Z & $p$ \\
\hline \multirow{3}{*}{ GCS score } & ASH-OP/ASH-FOL & $-8.215^{\mathrm{a}}$ & $<0.001$ \\
\cline { 2 - 4 } & ASH-FOL/ASH-INOP & $11.215^{\mathrm{a}}$ & $<0.001$ \\
\hline \multirow{2}{*}{ MLS level (mm) } & ASH-OP/ASH-FOL & $8.500^{\mathrm{a}}$ & 0.001 \\
\cline { 2 - 4 } & ASH-FOL/ASH-INOP & $-7.250^{\mathrm{a}}$ & 0.026 \\
\hline MLS-hematoma thickness ratio & ASH-OP/ASH-FOL & $-3.274^{\mathrm{b}}$ & 0.001 \\
\hline \multirow{3}{*}{ Duration of stay in ICU (day) } & ASH-OP/ASH-FOL & $-3.516^{\mathrm{b}}$ & $<0.001$ \\
\cline { 2 - 4 } & ASH-OP/ASH-INOP & $-2.454^{\mathrm{b}}$ & 0.014 \\
\hline \multirow{2}{*}{ Duration of stay in hospital (day) } & ASH-OP/ASH-FOL & $-3.619^{\mathrm{b}}$ & $<0.001$ \\
\cline { 2 - 4 } & ASH-OP/ASH-INOP & $-3.006^{\mathrm{b}}$ & 0.003 \\
\hline \multirow{2}{*}{ GOS score } & ASH-OP/ASH-FOL & $-2.915^{\mathrm{b}}$ & 0.004 \\
\cline { 2 - 4 } & ASH-FOL/ASH-INOP & $-3.205^{\mathrm{b}}$ & 0.001 \\
\hline
\end{tabular}

Abbreviations: GCS, Glasgow coma scale; GOS, Glasgow outcome scale; MLS, midline shift; Z: Z score.

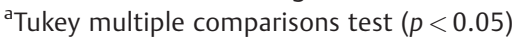

${ }^{\mathrm{b}}$ Mann-Whitney $\mathrm{U}$ test and Bonferroni correction test $(p<0.016)$

the first 4 hours of trauma. ${ }^{18,19}$ Bullock et al recommended surgery for patients with hematoma thickness $>10 \mathrm{~mm}$ or MLS level $>5 \mathrm{~mm}$, irrespective of the GCS scores. It was concluded that the trauma type, age, and gender had no effect on the short-term prognosis. ${ }^{8}$ Previous studies showed that platelet, glucose, and BUN values measured on admission to hospital were different between survived and nonsurvived patients. However, the Cox regression analysis showed that each one of these variables may not be a biomarker. 5,20,21 Although it has been reported in the literature that surgical drainage of a subdural hematoma ( $<4$ hours after trauma) could reduce mortality, it has been stated in several other studies that the majority of these patients have not benefitted from surgery and most have remained disabled or have died. ${ }^{22}$

In the present study, correlation test results also revealed that the GCS scores had a direct effect on the short-term prognosis. As the GOS scores are indirectly affected by the hematoma thickness and the amount of MLS level, when these values are found to be high, it could be predicted that the short-term prognosis could be worse. In addition, when the MLS-hematoma thickness ratio is found to be high, the duration of stay in ICU and hospital could be longer, suggesting that this could be used as an indirect prognostic marker in prediction of short-term prognosis. Briefly, these findings confirmed that GCS scores, hematoma thickness, MLS value, anisocoria, and the MLS-hematoma thickness ratio could each be used as indirect biomarkers of short-term prognosis and mortality risk. Additionally, logistic regression analysis revealed that GCS was seen to be the best parameter for the prediction of mortality likelihood. On the other hand, correlation test results revealed that neither comorbidity nor usage of the antiaggregant or anticoagulant drug could affect the results of the study. Furthermore, in contrast to the literature, no correlation was found between the time taken from admission to hospital to the surgical drainage of ASH and the GCS, GOS, and mortality rates.

Interestingly, blood count parameters were not different among the patient groups in present study. However, the leukocyte count and neutrophil count of the majority of the patients were determined to be above the normal values. These findings suggested that ASH could cause an increase in leukocyte and neutrophil counts, and this could lead to a series of inflammatory processes against damaged neural tissues in the acute period. Moreover, correlation analysis results showed a negative correlation between the GCS scores and leukocyte count and a positive correlation between GCS scores and GOS scores, and it was therefore thought that the short-term prognosis of these patients could be poor when the leukocyte count is determined to be high. In addition, a negative correlation was determined between GCS scores and serum glucose, ALT, and AST levels. With these findings, it could be said that when the leukocyte count values, glucose, ALT, and AST levels were measured to be high, GCS scores and, indirectly, GOS scores could be measured low. On the other hand, ROC curve analysis results demonstrated that when GCS score was $>8$, this could be an effective parameter in the decision-making for conservative treatment rather than surgical treatment. Therefore, low GCS score directly and leukocyte count value and glucose, ALT, and AST level values indirectly could help in deciding for surgical treatment for the patients with ASH. Moreover, when the positive correlation between GCS and GOS scores is taken into consideration, in conditions where the leukocyte count, glucose, ALT, and AST levels are high on admission to hospital and GCS scores are low, it suggests that these parameters could indirectly affect the short-term prognosis. Thus, it was concluded that leukocyte count, serum glucose, ALT, and AST values could each be used as direct or indirect biomarkers in the prediction of short-term prognosis of patients with ASH. Moreover, a positive 
Predictive Markers in Acute Subdural Hematoma Bakar et al.

Table 6 Table reveals the demographic, radiographic, and biochemical analyses results of all the patients when they were grouped as survived and nonsurvived

\begin{tabular}{|c|c|c|c|c|}
\hline & & Nonsurvived & Survived & \\
\hline Variable & & $\begin{array}{l}\text { Mean } \pm S D / \\
\text { Median (min-max) } \\
N(\%)\end{array}$ & $\begin{array}{l}\text { Mean } \pm \mathrm{SD} / \\
\text { Median (min-max) } \\
N(\%)\end{array}$ & $p$ \\
\hline Age (year) & & $56.29 \pm 23.45$ & $48.93 \pm 21.95$ & $0.399^{a}$ \\
\hline \multirow[t]{2}{*}{ Gender } & Male & $12(42.9 \%)$ & $11(39.3 \%)$ & $0.622^{c}$ \\
\hline & Female & $2(7.1 \%)$ & $3(10.7 \%)$ & \\
\hline \multirow[t]{2}{*}{ Etiology } & $\mathrm{FFH}$ & $9(32.1 \%)$ & $6(21.4 \%)$ & $0.256^{c}$ \\
\hline & TA & $5(17.9 \%)$ & $8(28.6 \%)$ & \\
\hline GCS score & & $6.36 \pm 4.25$ & $13.00 \pm 3.94$ & $<0.001^{a}$ \\
\hline Hematoma thickness value (mm) & & $12.21 \pm 5.33$ & $8.24 \pm 4.68$ & $0.046^{a}$ \\
\hline MLS level (mm) & & $6.23 \pm 6.99$ & $2.43 \pm 5.08$ & $0.112^{\mathrm{a}}$ \\
\hline MLS-hematoma thickness ratio & & $0.32(0.10-2)$ & $0.20(0.04-1.50)$ & $0.160^{b}$ \\
\hline \multirow[t]{2}{*}{ Presence of anisocoria } & No & $3(10.7 \%)$ & $11(39.3 \%)$ & $0.002^{c}$ \\
\hline & Yes & $11(39.3 \%)$ & $3(10.7 \%)$ & \\
\hline Hemoglobin level (g/dL) & & $13.61 \pm 1.59$ & $14.48 \pm 2.27$ & $0.250^{\mathrm{a}}$ \\
\hline Leukocyte count (uL) & & $15132 \pm 6556.76$ & $13406 \pm 4465.23$ & $0.423^{\mathrm{a}}$ \\
\hline Neutrophil count (uL) & & $11125 \pm 7198.32$ & $9092 \pm 4703.94$ & $0.384^{a}$ \\
\hline Lymphocyte count (uL) & & $2423 \pm 2587.25$ & $3302 \pm 2833.98$ & $0.399^{a}$ \\
\hline Monocyte count (uL) & & $542 \pm 272.73$ & $752 \pm 296.74$ & $0.062^{\mathrm{a}}$ \\
\hline Eosinophil count (uL) & & $121 \pm 177.65$ & $214 \pm 181.64$ & $0.186^{a}$ \\
\hline Basophil count (uL) & & $80 \pm 109.02$ & $51 \pm 47.02$ & $0.360^{\mathrm{a}}$ \\
\hline Platelet count (uL) & & $199438 \pm 93610.49$ & $255428 \pm 73982.03$ & $0.091^{\mathrm{a}}$ \\
\hline Neutrophil to lymphocyte ratio & & $5.78(0.85-73.74)$ & $2.88(0.74-44.72)$ & $0.270^{\mathrm{b}}$ \\
\hline Platelet to lymphocyte ratio & & $105(2.20-773.97)$ & $103.86(32.89-553.53)$ & $0.783^{b}$ \\
\hline Glucose (mg/dL) & & $179.06 \pm 110.98$ & $143.71 \pm 48.55$ & $0.435^{\mathrm{a}}$ \\
\hline Sodium (mmol/L) & & $142(145-154)$ & $139(134-146)$ & $0.851^{\mathrm{b}}$ \\
\hline Potassium (mmol/L) & & $4.23(2.88-5.90)$ & $4.29(3.33-5.54)$ & $0.911^{\mathrm{b}}$ \\
\hline Blood urea nitrogen $(\mathrm{mg} / \mathrm{dL})$ & & $35.74 \pm 13.86$ & $30.39 \pm 14.88$ & $0.426^{\mathrm{a}}$ \\
\hline Creatinine (mg/dL) & & $0.95(0.53-2.62)$ & $0.93(0.68-1.24)$ & $0.911^{\mathrm{b}}$ \\
\hline Aspartate aminotransferase (u/L) & & $26(16-468)$ & $32(14-80)$ & $1.000^{\mathrm{b}}$ \\
\hline Alanine aminotransferase (u/L) & & $19(10-33)$ & $18(9--39)$ & $0.654^{\mathrm{b}}$ \\
\hline C-reactive protein $(\mathrm{mg} / \mathrm{dL})$ & & $35.81 \pm 65.31$ & $19.31 \pm 34.03$ & $0.541^{\mathrm{a}}$ \\
\hline Duration of stay in ICU (day) & & $10.50(2-102)$ & $5(2-28)$ & $0.059^{b}$ \\
\hline Duration of stay in hospital (day) & & $15(2-102)$ & $6(3-28)$ & $0.097^{\mathrm{b}}$ \\
\hline GOS score & & $1(1-1)$ & $5(2-5)$ & $<0.001^{b}$ \\
\hline
\end{tabular}

Abbreviations: FFH, fall from a height; GCS, Glasgow coma scale; GOS, Glasgow outcome scale; ICU, intensive care unit; Max, maximum; Min, minimum; MLS, midline shift; $N$, number of patients; SD, standard deviation; TA: traffic accidents.

andependent samples $t$-test $(p<0.05)$

${ }^{\mathrm{b}}$ Mann-Whitney U test $(p<0.05)$

'Pearson's Chi-square test $(p<0.05)$

correlation was determined between the decision for surgery and the leukocyte count. In contrast, a negative correlation was determined between the GCS scores and leukocyte count and a positive correlation between GCS and GOS scores. From these findings, it was thought that when the leukocyte count was elevated, the GCS scores could be low and could indirectly increase the likelihood of a decision being made for surgery, which would indirectly have a negative effect on the short-term prognosis of the patient. However, it was suggested that these findings should be supported and 


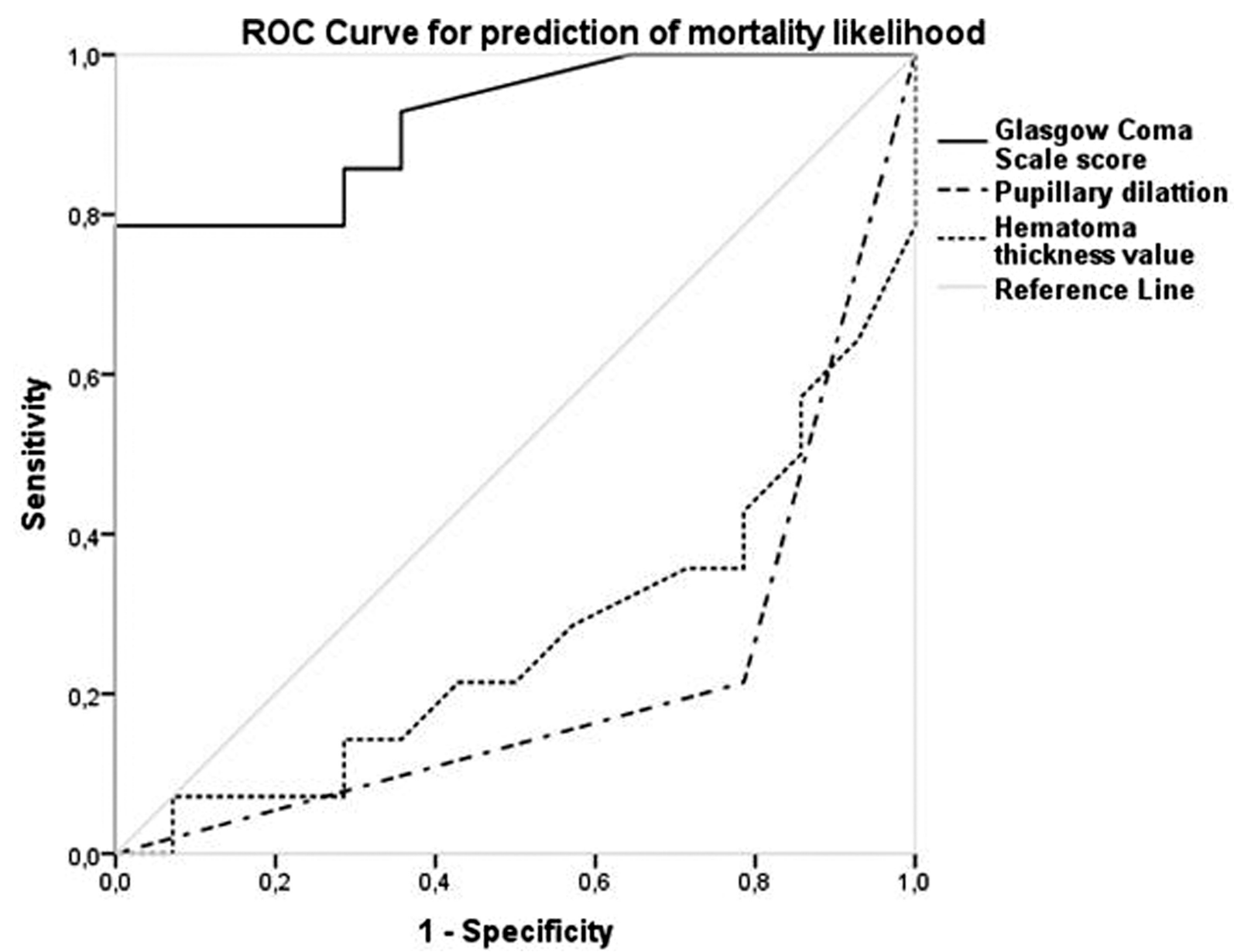

Fig. 5 The receiver operating characteristic (ROC) curve plot shows the parameters that can predict the mortality risk in patients with acute subdural hematoma (ASH).

explained by studies with a more advanced and large number of patients.

\section{Study Limitations}

There were some limitations to this study. First, this singlecenter retrospective study contained low number of patients, which could have caused a statistical power loss. However, the g-power analysis revealed that the number of patients included in the study formed a sufficient sample. Second, no intracranial pressure monitoring could be performed on any patient because of the financial restriction. Third, the long-term follow-up results of patients were not included in this study because that was both beyond the scope of the study and most of the patients were residents in other cities. Finally, the radiological imaging of the patients was made with CT and therefore there was no evaluation of magnetic resonance imaging and other radiological imaging that can better show the brain structures and neural tissue.

\section{Conclusion}

Study results suggested that GCS scores, MLS level, MLShematoma thickness ratio, anisocoria, and leukocyte count value that were obtained at admission to the hospital could help the surgeon in decision-making for surgical intervention in patients with traumatic ASH.

It was also considered that GCS scores, hematoma thickness, MLS level, leukocyte count, serum glucose, ALT, and AST levels could each be used as biomarkers in the direct or indirect prediction of short-term prognosis.

Finally, GCS scores, hematoma thickness value, and the presence of anisocoria could be used as biomarkers in the prediction of the mortality risk.

\section{Informed Consent}

Informed consent was obtained from all individual participants or their parents who were included in this study.

\section{Authors' Contributions}

All of the authors declare that they have all participated in the design, execution, and analysis of the paper, and that they have approved the final version:

- Concept and design: B.B.

- Definition of intellectual content: B.B., M.O.

- Literature search: B.B., U.Y.

- Data acquisition: A.O., I.U.B.

- Data analysis: B.B., M.O., U.Y.

- Statistical analysis: B.B. 
- Manuscript preparation: B.B.

- Manuscript editing: M.O.

- Manuscript review: B.B., M.O., U.Y.

\section{Funding}

None.

\section{Conflict of Interest}

None declared.

\section{Reference}

1 Gurer B, Kertmen H, Yilmaz ER, Dolgun H, Hasturk AE, Sekerci Z. The surgical outcome of traumatic extraaxial hematomas causing brain herniation. Turk Neurosurg 2017;27(01):37-52

2 Koç RK, Akdemir H, Oktem IS, Meral M, Menkü A Acute subdural hematoma: outcome and outcome prediction. Neurosurg Rev 1997;20(04):239-244

3 Badri S, Chen J, Barber J, et al. Mortality and long-term functional outcome associated with intracranial pressure after traumatic brain injury. Intensive Care Med 2012;38(11):1800-1809

4 Schreiber MA, Aoki N, Scott BG, Beck JR. Determinants of mortality in patients with severe blunt head injury. Arch Surg 2002;137(03):285-290

5 Kalayci M, Aktunç E, Gül S, et al. Decompressive craniectomy for acute subdural haematoma: an overview of current prognostic factors and a discussion about some novel prognostic parametres. J Pak Med Assoc 2013;63(01):38-49

6 Teasdale G, Jennett B. Assessment of coma and impaired consciousness. A practical scale. Lancet 1974;2(7872):81-84

7 McMillan T, Wilson L, Ponsford J, Levin H, Teasdale G, Bond M. The Glasgow Outcome Scale - 40 years of application and refinement. Nat Rev Neurol 2016;12(08):477-485

8 Bullock MR, Chesnut R, Ghajar J, et al; Surgical Management of Traumatic Brain Injury Author Group. Surgical management of traumatic parenchymal lesions. Neurosurgery 2006;58(03): S25-S46, discussionSi-iv

9 Wong DK, Lurie F, Wong LL. The effects of clopidogrel on elderly traumatic brain injured patients. J Trauma 2008;65(06): 1303-1308

10 Mathew P, Oluoch-Olunya DL, Condon BR, Bullock R. Acute subdural haematoma in the conscious patient: outcome with initial non-operative management. Acta Neurochir (Wien) 1993; 121(3-4):100-108

11 Servadei F, Nasi MT, Giuliani G, et al. CT prognostic factors in acute subdural haematomas: the value of the 'worst' CT scan. Br J Neurosurg 2000;14(02):110-116

12 Chesnut RM, Marshall LF, Klauber MR, et al. The role of secondary brain injury in determining outcome from severe head injury. J Trauma 1993;34(02):216-222

13 Signorini DF, Andrews PJ, Jones PA, Wardlaw JM, Miller JD. Predicting survival using simple clinical variables: a case study in traumatic brain injury. J Neurol Neurosurg Psychiatry 1999;66 (01):20-25

14 Cagetti B, Cossu M, Pau A, Rivano C, Viale G. The outcome from acute subdural and epidural intracranial haematomas in very elderly patients. Br J Neurosurg 1992;6(03):227-231

15 Jamjoom A. Justification for evacuating acute subdural haematomas in patients above the age of 75 years. Injury 1992; 23(08):518-520

16 Tien HC, Cunha JR, Wu SN, et al. Do trauma patients with a Glasgow Coma Scale score of 3 and bilateral fixed and dilated pupils have any chance of survival? J Trauma 2006;60(02):274-278

17 Karibe H, Hayashi T, Hirano T, Kameyama M, Nakagawa A Tominaga T. Surgical management of traumatic acute subdural hematoma in adults: a review. Neurol Med Chir (Tokyo) 2014;54 (11):887-894

18 Seelig JM, Becker DP, Miller JD, Greenberg RP, Ward JD, Choi SC. Traumatic acute subdural hematoma: major mortality reduction in comatose patients treated within four hours. N Engl J Med 1981;304(25):1511-1518

19 Tien HC, Jung V, Pinto R, Mainprize T, Scales DC, Rizoli SB. Reducing time-to-treatment decreases mortality of trauma patients with acute subdural hematoma. Ann Surg 2011;253 (06):1178-1183

20 Kreutziger J, Schlaepfer J, Wenzel V, Constantinescu MA. The role of admission blood glucose in outcome prediction of surviving patients with multiple injuries. J Trauma 2009;67(04):704-708

21 Melo JR, Di Rocco F, Blanot S, et al. Acute hyperglycemia is a reliable outcome predictor in children with severe traumatic brain injury. Acta Neurochir (Wien) 2010;152(09):1559-1565

22 Alessandri B, Nishioka T, Heimann A, Bullock RM, Kempski O. Caspase-dependent cell death involved in brain damage after acute subdural hematoma in rats. Brain Res 2006;1111(01): 196-202 